\title{
Similarity treatment for MHD free convective boundary layer flow of a class of Non-Newtonian Fluids \\ Department of Mathematics
} Sarvajanik College of Engineering and

Technology

Surat-395 001, Gujarat

Munir G. Timol

Department of Mathematics Veer Narmad South Gujarat University Surt-395007, Gujarat
Deductive group symmetry treatment is appied to derive the similarity transformations for the free convective boundary layer flow of a class of non-Newtonian fluids past over a two-dimensional surface and flowing under the influence of transverse magnetic field. Numerical solutions are obtained for particular Non-Newtonian fluid model namely Prandtl Eyring fluid, in a graphical form. The important physical quantities like velocity distribution, skin friction coefficent and temperature variations are discussed.

Keywords: Non-Newtonian fluid, Deuctive group symmetry, Similarity transformation, MHD, Prandtl Eyring fluid, Boundary layer theory.

\section{INTRODUCTION}

The classical theory of fluid mechanics is based upon the hypothesis of a linear relationship between two tensor components, shearing stress and rate of strain as,

$$
\tau=-\mu \frac{\partial u}{\partial y}
$$

The fluids with properties different from that described by equation (1), called Non-Newtonian fluids.

Flow of Non-Newtonian fluids has attained a great success in the theory of fluid mechanics due to its applications in biological sciences and industry. Problems involving Non-Newtonian fluid models have been studied by the many researchers since last decades. Several techniques are found to analyze and derive the solutions of governing equations. Some of these are cited in Refs. [1-9]. The similarity technique plays an important role in problem analysis, especially in the boundary layer flows. The similarity method involves the determination of similarity variables which reduce the system of governing partial differential equations in to ordinary differential equations. Indeed similarity solution is the only class of more accurate solution for the governing differential equations. In the present work we have applied similarity treatment for the particular boundary layer problem.

In the literature several information are available on similarity solutions for the natural convective heat transfer of a Non-Newtonian fluids [See 10-12]. Researchers have presented works on flow in an electrically conducting Non-Newtonian fluid over a stretching sheet [see 13-19]. At this point it is worth to note that most of the work has been done for NonNewtonian power-law fluids; this is because of its mathematical simplicity. However there are empirical

Received: May 2015, Accepted: February 2016

Correspondence to: Dr. Rajesh M. Darji

Department of Mathematics, Sarvajanik College of

Engineering and Technology, Gujarat, India

E-mail: rmdarji@gmail.com

doi:10.5937/fmet1602197D

(C) Faculty of Mechanical Engineering, Belgrade. All rights reserved
Non-Newtonian fluid models based on functional relationship between shear stress and rate of the strain are available [20]. In present work we concentrate our discussion on the similarity solution of steady laminar natural convection flows of generalized Non-Newtonian fluid. Such a class of fluids are severely omitted in the analysis due to mathematical complicity of its nonlinear stress-strain relationship. Further, from these charts, we noticed that all the similarity solutions presented there in are derived either by adopting or by ad-hoc assumption on similarity variables. In the context of this work it is necessary to develop systematical group transformation for similarity solution. Hence, present work focused on deductive group symmetry analysis based on general group of transformations. The analysis is applied to the particular problem of boundary layer theory. We investigate the MHD boundary layer flow of a class of Non-Newtonian fluids characterized by the property that its stress tensor component $\tau_{i j}$ can be related to the strain rate component $e_{i j}$ by the arbitrary continuous function of the type

$$
\Omega\left(\tau_{i j}, e_{i j}\right)=0
$$

The similarity equations obtained are more general and systematic along with auxiliary conditions. Recently this method has been successfully applied to various non-linear problems by Abd-el-Malek et al [21], Adnan et al [22], Darji and Timol [23, 24].

\section{GOVERNING EQUATIONS}

Consider the steady laminar natural convection flow of a non-Newtonian fluid over a vertical permeable surface, in the presence of transverse magnetic field. Consider the vertical upward along the surface as positive $\mathrm{x}$-direction, and the origin is fixed (Fig. 1). The transverse electrically conducting variable magnetic field of the strength $B(x)$ is applied normal to the $X$-axis. It is assumed that the magnetic Reynolds number $R e_{m}$ is very small; i.e. $\operatorname{Re}_{m}=\mu_{0} \sigma L<<1$, where $\mu_{0}$ is the magnetic permeability, $L$ is the reference length of the plate and $\sigma$ is the electric conductivity. We neglect the induced 
magnetic field, which is small in comparison with the applied magnetic field. Also for a class of NonNewtonian fluids, the stress-strain relation, under the boundary layer assumption can be found in the form of arbitrary function with only non-vanishing component $\tau_{y x}$. Then the relation (2) can be given by [see 20]

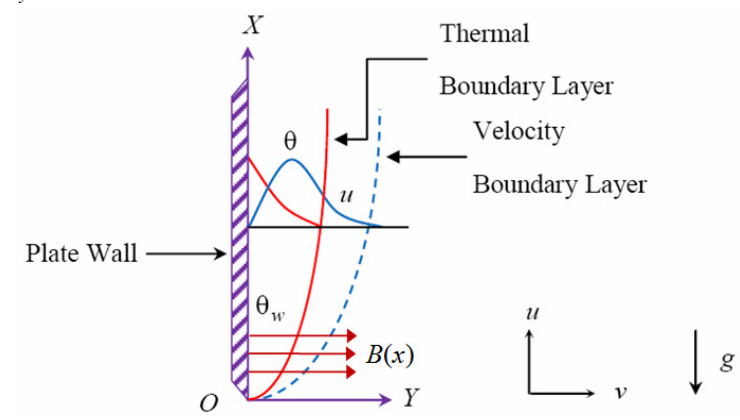

Figure 1. Schematic diagram of MHD natural convection

$$
\Omega\left(\tau_{y x}, \frac{\partial u}{\partial y}\right)=0
$$

Using boundary layer approximations, the governing equations for a class of non-Newtonian fluids are given by [See 28, 29]:

Continuity Equation:

$$
\frac{\partial u}{\partial x}+\frac{\partial v}{\partial y}=0
$$

Momentum Equation:

$$
u \frac{\partial u}{\partial x}+v \frac{\partial v}{\partial y}=\frac{1}{\rho} \frac{\partial}{\partial y}\left(\tau_{y x}\right)+g \beta^{\prime} \theta-\frac{\sigma B^{2}(x)}{\rho} u
$$

Energy Equation:

$$
u \frac{\partial \theta}{\partial x}+v \frac{\partial \theta}{\partial y}=\alpha^{\prime} \frac{\partial^{2} \theta}{\partial y^{2}}
$$

Together with boundary conditions:

$$
\begin{aligned}
& \forall x, \quad u=v=0, \quad \theta=\theta_{w}(x) \text { at } y=0 \\
& \forall x, \quad u=\theta=0 \quad \text { as } y \rightarrow \infty
\end{aligned}
$$

where $\alpha^{\prime}$ is thermal diffusivity, $\beta^{\prime}$ is the volumetric thermal expansion coefficient.

Introducing the following dimensionless quantities,

$$
\begin{gathered}
x^{*}=\frac{G r}{L} x, \quad y^{*}=\left(\frac{R e}{3} \cdot G r\right)^{1 / 2} \frac{y}{L}, \\
u^{*}=\frac{u}{U_{\infty}}, \quad v^{*}=\left(\frac{R e}{3 G r}\right)^{1 / 2} \frac{v}{U_{\infty}}, \\
\tau_{y x}^{*}=\left(\frac{R e}{3 G r}\right)^{1 / 2} \frac{\tau_{y x}}{\rho U_{\infty}^{2}}, \quad \theta^{*}=\frac{\theta}{\left(\theta_{w}-\theta_{\infty}\right)}, \quad \theta_{w}^{*}=\frac{\theta_{w}}{\left(\theta_{w}-\theta_{\infty}\right)}, \\
\operatorname{Re}=\frac{U_{\infty} L}{v}, \quad P_{r}=\frac{U_{0} L}{\alpha^{\prime} \operatorname{Re}}, \quad G r=\frac{L}{U_{\infty}^{2}} g \beta^{\prime}\left(\theta_{w}-\theta_{\infty}\right)
\end{gathered}
$$

where $\mathrm{L}$ is the reference length of plate, $U_{0}$ is the reference velocity, $U_{\infty}$ is the far velocity (near boundary layer), $\theta_{w}$ and $\theta_{\infty}$ are the absolute temperatures of fluid near plate wall and near boundary layer respectively.
Substitute the values in (3) to (7) along with nondimensional stream function $\psi^{*}\left(x^{*}, y^{*}\right)$ such that $u^{*}=\frac{\partial \psi^{*}}{\partial y^{*}}$ and $v^{*}=-\frac{\partial \psi^{*}}{\partial x^{*}}$, and dropping the asterisks (for simplicity), we get

$$
\begin{gathered}
\Omega\left(\tau_{y x}, \frac{\partial u}{\partial y}\right)=0 \\
\frac{\partial \psi}{\partial y} \frac{\partial^{2} \psi}{\partial y \partial x}-\frac{\partial \psi}{\partial x} \frac{\partial^{2} \psi}{\partial y^{2}}=\frac{\partial}{\partial y}\left(\tau_{y x}\right)+\theta-b B^{2}(x) \frac{\partial \psi}{\partial y} \\
\frac{\partial \psi}{\partial y} \frac{\partial \theta}{\partial x}-\frac{\partial \psi}{\partial x} \frac{\partial \theta}{\partial y}=\frac{1}{3 P_{r}} \frac{\partial^{2} \theta}{\partial y^{2}}
\end{gathered}
$$

in which $b=\sigma / \rho U_{\infty}$, together with boundary conditions:

$$
\begin{aligned}
& \frac{\partial \psi}{\partial y}(x, 0)=\frac{\partial \psi}{\partial x}(x, 0)=0, \quad \theta(x, 0)=\theta_{w}(x) \\
& \frac{\partial \psi}{\partial y}(x, \infty)=\theta(x, \infty)=0
\end{aligned}
$$

\section{SIMILARITY ANALYSIS}

We now seek some sort of transformation, namely, similarity transformation which transforms the partial differential Eqs (8) to (10) into the ordinary differential equations along with appropriate auxiliary conditions (11). To search this transformation, the one-parameter general deductive group of transformations is introduced as:

$$
G: \quad \bar{Q}(a)=\mathfrak{\aleph}^{Q}(a) s+\mathfrak{R}^{Q}
$$

where $Q$ stands for $x, y, \psi, \theta, \tau_{y x}, B, \aleph^{\prime} s$ and $\Re^{\prime} s$ are real-valued and at least differential in the real argument a.

To transform the differential equation, transformations of the derivatives of $\psi$ can be obtained from $G$ via chain-rule operations.

\section{a. Invariance analysis}

Equations (8) to (10) are said to be invariantly transformed, for some functions $\xi_{i}(a)$ whenever,

$$
\begin{aligned}
& \Omega\left(\bar{\tau}_{\bar{y} \bar{x}}, \frac{\partial^{2} \bar{\psi}}{\partial \bar{y}^{2}}\right)=\xi_{1}(a) \Omega\left(\tau_{y x}, \frac{\partial^{2} \psi}{\partial y^{2}}\right) \\
& \frac{\partial \bar{\psi}}{\partial \bar{y}} \frac{\partial^{2} \bar{\psi}}{\partial \bar{y} \partial \bar{x}}-\frac{\partial \bar{\psi}}{\partial \bar{x}} \frac{\partial^{2} \bar{\psi}}{\partial \bar{y}^{2}}-\frac{\partial}{\partial \bar{y}}\left(\bar{\tau}_{\bar{y} \bar{x}}\right)-\bar{\theta}+b \bar{B}^{2}(\bar{x}) \frac{\partial \bar{\psi}}{\partial \bar{y}} \\
& =\xi_{2}(a)\left[\begin{array}{l}
\frac{\partial \psi}{\partial y} \frac{\partial^{2} \psi}{\partial y \partial x}-\frac{\partial \psi}{\partial x} \frac{\partial^{2} \psi}{\partial y^{2}} \\
-\frac{\partial}{\partial y}\left(\tau_{y x}\right)-\theta+b B^{2}(x) \frac{\partial \psi}{\partial y}
\end{array}\right] \\
& \frac{\partial \bar{\psi}}{\partial \bar{y}} \frac{\partial \bar{\theta}}{\partial \bar{x}}-\frac{\partial \bar{\psi}}{\partial \bar{x}} \frac{\partial \bar{\theta}}{\partial \bar{y}}-\frac{1}{3 P_{r}} \frac{\partial^{2} \bar{\theta}}{\partial \bar{y}^{2}} \\
& =\xi_{3}(a)\left[\frac{\partial \psi}{\partial y} \frac{\partial \theta}{\partial x}-\frac{\partial \psi}{\partial x} \frac{\partial \theta}{\partial y}-\frac{1}{3 P_{r}} \frac{\partial^{2} \theta}{\partial y^{2}}\right]
\end{aligned}
$$


Substituting the values from (12), using chainrule operation in above equation, yields

$\Omega\left(\aleph^{\tau_{y x}} \tau_{y x}+\Re^{\tau_{y x}}, \frac{\aleph^{\psi}}{\left(\aleph^{y}\right)^{2}} \frac{\partial^{2} \psi}{\partial y^{2}}\right)=\xi_{1}(a) \Omega\left(\tau_{y x}, \frac{\partial^{2} \psi}{\partial y^{2}}\right)(16)$

$\frac{\left(\boldsymbol{\aleph}^{\psi}\right)^{2}}{\boldsymbol{\aleph}^{x}\left(\boldsymbol{\aleph}^{y}\right)^{2}}\left[\frac{\partial \psi}{\partial y} \frac{\partial^{2} \psi}{\partial y \partial x}-\frac{\partial \psi}{\partial x} \frac{\partial^{2} \psi}{\partial y^{2}}\right]-\frac{\aleph^{\tau_{y x}}}{\aleph^{y}} \frac{\partial}{\partial y}\left(\tau_{y x}\right)$

$-\left(\aleph^{\theta} \theta+\mathfrak{R}^{\theta}\right)+b\left(\aleph^{B} B+\mathfrak{R}^{B}\right)^{2} \frac{\aleph^{\psi}}{\boldsymbol{\aleph}^{y}} \frac{\partial \psi}{\partial y}$

$=\xi_{2}(a)\left[\begin{array}{l}\frac{\partial \psi}{\partial y} \frac{\partial^{2} \psi}{\partial y \partial x}-\frac{\partial \psi}{\partial x} \frac{\partial^{2} \psi}{\partial y^{2}} \\ -\frac{\partial}{\partial y}\left(\tau_{y x}\right)-\theta+b B^{2} \frac{\partial \psi}{\partial y}\end{array}\right]$

$\frac{\aleph^{\psi} \aleph^{\theta}}{\aleph^{x} \aleph^{y}}\left[\frac{\partial \psi}{\partial y} \frac{\partial \theta}{\partial x}-\frac{\partial \psi}{\partial x} \frac{\partial \theta}{\partial y}\right]-\frac{\aleph^{\theta}}{\left(\aleph^{y}\right)^{2}}\left[\frac{1}{3 P_{r}} \frac{\partial^{2} \theta}{\partial y^{2}}\right]$

$=\xi_{3}(a)\left[\frac{\partial \psi}{\partial y} \frac{\partial \theta}{\partial x}-\frac{\partial \psi}{\partial x} \frac{\partial \theta}{\partial y}-\frac{1}{3 P_{r}} \frac{\partial^{2} \theta}{\partial y^{2}}\right]$

The invariance of equations (16)-(18) together with boundary conditions (10), implies that

$$
\begin{aligned}
& \mathfrak{R}^{\theta}=\mathfrak{R}^{\tau_{y x}}=\mathfrak{R}^{y}=\mathfrak{R}^{\psi}=\mathfrak{R}^{B}=0, \\
& \mathfrak{\aleph}^{\tau_{y x}}=\frac{\mathfrak{\aleph}^{\psi}}{\left(\boldsymbol{\aleph}^{y}\right)^{2}}=1=\xi_{1}(a), \\
& \frac{\left(\boldsymbol{\aleph}^{\psi}\right)^{2}}{\boldsymbol{\aleph}^{x}\left(\boldsymbol{\aleph}^{y}\right)^{2}}=\frac{\boldsymbol{\aleph}^{\tau_{y x}}}{\boldsymbol{\aleph}^{y}}=\boldsymbol{\aleph}^{\theta}=\frac{\left(\boldsymbol{\aleph}^{B}\right)^{2} \boldsymbol{\aleph}^{\psi}}{\boldsymbol{\aleph}^{y}}=\xi_{2}(a), \\
& \frac{\boldsymbol{\aleph}^{\psi} \boldsymbol{\aleph}^{\theta}}{\boldsymbol{\aleph}^{x} \boldsymbol{\aleph}^{y}}=\frac{\boldsymbol{\aleph}^{\theta}}{\left(\boldsymbol{\aleph}^{y}\right)^{2}}=\xi_{3}(a),
\end{aligned}
$$

These yield

$$
\mathfrak{\aleph}^{x}=\left(\boldsymbol{\aleph}^{y}\right)^{3}, \boldsymbol{\aleph}^{\psi}=\left(\boldsymbol{\aleph}^{y}\right)^{2}, \mathfrak{\aleph}^{\theta}=\frac{1}{\boldsymbol{\aleph}^{y}}, \boldsymbol{\aleph}^{\tau_{y x}}=1, \mathfrak{\aleph}^{B}=\frac{1}{\boldsymbol{\aleph}^{y}} .
$$

Finally, we get the one-parameter group $G$, which transforms invariantly the system of equations (8)-(10) along with the auxiliary conditions (11).

$$
G:\left\{\begin{array}{l}
\bar{x}=\left(\aleph^{y}\right)^{3} x+\mathfrak{R}^{x}, \bar{y}=\aleph^{y} y \\
\bar{\psi}=\left(\aleph^{y}\right)^{2} \psi, \bar{\theta}=\frac{1}{\aleph^{y}} \theta, \bar{B}=\frac{1}{\aleph^{y}} B, \quad \bar{\tau}_{\bar{y}} \bar{x}=\tau_{y x}
\end{array}\right.
$$

\section{b. The complete set of absolute invariants}

Now we want to develop a complete set of absolute invariants so that the original problem (8)-(10) will be transformed into similarity equations under the derived deductive group (21).

If $\eta=\eta(x, y)$ is the absolute invariant of the independent variables, then variables of the four absolute invariants for dependent variables $\psi, \theta, \tau_{y x}, B$ are given by

$$
g_{j}\left(x, y, \psi, \theta, \tau_{y x}, B\right)=F_{j}(\eta), \quad j=1,2,3,4 .
$$

and can be obtained by the following first-order linear partial differential equation: (see Morgan [25], Moran and Gaggioli [26])

$$
\sum_{i=1}^{6}\left(\alpha_{i} Q_{i}+\beta_{i}\right) \frac{\partial g}{\partial Q_{i}}=0, \quad Q_{i}=x, y, \psi, \theta, \tau_{y x}, B
$$

where,

$$
\alpha_{i}=\left.\frac{\partial \aleph^{i}}{\partial a}\right|_{a=a^{0}} \quad \text { and } \quad \beta_{i}=\left.\frac{\partial \Re^{i}}{\partial a}\right|_{a=a^{0}}(i=1, . .6)
$$

and ' $a$ ', denotes the value of ' $a$ ' which yields the identity element of the group $G$.

Since $\mathfrak{R}^{\theta}=\mathfrak{R}^{\tau_{y x}}=\mathfrak{R}^{\psi}=\mathfrak{R}^{y}=\mathfrak{R}^{B}=0$ implies that $\beta_{1}=\beta_{2}=\beta_{3}=\beta_{4}=\beta_{5}=\beta_{6}=0$ and from (24) we get $\alpha_{1}=3 \alpha_{2}=\frac{3}{2} \alpha_{3}=-\alpha_{4}=-\alpha_{6}, \alpha_{5}=0$.

Equation (23) yields:

$$
\begin{aligned}
& \left(\alpha_{1} x+\beta_{1}\right) \frac{\partial g}{\partial x}+\left(\frac{\alpha_{1} y}{3}\right) \frac{\partial g}{\partial y}+\left(\frac{2 \alpha_{1} \psi}{3}\right) \frac{\partial g}{\partial \psi}-\left(\frac{\alpha_{1} \theta}{3}\right) \frac{\partial g}{\partial \theta} \\
& +(0) \frac{\partial g}{\partial \tau_{y x}}-\left(\frac{\alpha_{6} B}{3}\right) \frac{\partial B}{\partial \theta}=0 .
\end{aligned}
$$

The corresponding characteristic equation of (25) is

$$
\frac{d x}{(x+\beta)}=\frac{3 d y}{y}=\frac{3 d \psi}{2 \psi}=-\frac{3 d \theta}{\theta}=\frac{d \tau_{y x}}{0}=-\frac{3 d B}{B}
$$

where $\beta=\beta_{1} / 3 \alpha_{1}$

Applying the variable separable method, the absolute invariants of independent and dependent variables owing the equation (25) are given by

$$
\left.\begin{array}{l}
\eta(x, y)=y(x+\beta)^{-1 / 3} \\
F_{1}(\eta)=\psi(x+\beta)^{-2 / 3}=F(\eta) \\
F_{2}(\eta)=\theta(x+\beta)^{1 / 3}=G(\eta) \\
F_{3}(\eta)=\tau_{y x}=H(\eta) \\
F_{4}(\eta)=B(x+\beta)^{1 / 3}=B_{0}
\end{array}\right\}
$$

As $B(x)$ is a functions of $x$ only, $F_{4}(\eta)$ must be constant say $B_{0}$.

The group transformation of absolute invariants is

$$
\begin{aligned}
& \eta(x, y)=y(x+\beta)^{-1 / 3} \\
& \psi=(x+\beta)^{2 / 3} F(\eta) \\
& \theta=(x+\beta)^{-1 / 3} G(\eta) \\
& \tau_{y x}=H(\eta) \\
& B=B_{0}(x+\beta)^{-1 / 3}
\end{aligned}
$$

\section{c. Reduction to ordinary differential equations}

Substituting the values of derivatives from (28) in equations (8)-(10), yields the following system of nonlinear ordinary differential equations. 


$$
\left.\begin{array}{l}
\left(F^{\prime}\right)^{2}-2 F F^{\prime}-3 H^{\prime}-G+3 M F^{\prime}=0 . \\
2 F G^{\prime}+F^{\prime} G+\frac{1}{P_{r}} G^{\prime}=0 .
\end{array}\right\}
$$

where $M n=\sigma B_{0}^{2} / \rho U_{\infty}$ is the magnetic parameter and $H(\eta)$ is similarity variable related to non-dimensional strain-stress relation

$$
\Omega\left(H, F^{\prime \prime}\right)=0
$$

Together with boundary conditions, subject to $\theta_{w}(x)=(x+\beta)^{-\frac{1}{3}}$ are

$$
\begin{aligned}
& F(0)=F^{\prime}(0)=0, \quad G(0)=1, \\
& F^{\prime}(\infty)=G(\infty)=0
\end{aligned}
$$

\section{PRANDTL EYRING FLUID MODEL}

Non-Newtonian fluid models based on functional relationship between shear-stress and rate of the strain, shown by equation (3), are defined by various empirical explicit or implicit functional relations See [20, 27]. Among these models most research work has been so far carried out on power-law fluid model, this is because of its mathematical simplicity. On the other hand fluid models other than the Power-law model presented in Table 1 are mathematically more complex and the nature of partial differential equations governing these flows is too non-liner boundary value type and hence their analytical or numerical solution is a bit difficult. For the present study the Prendtl Eyring model, although mathematically more complex, is chosen mainly due to two reasons. Firstly, it can be deduced from kinetic theory of liquids rather than the empirical relation as in the powerlaw model. Secondly, it correctly reduces to Newtonian behavior for both low and high shear rate. This reason is somewhat opposite to the pseudo plastic system, whereas the power-law model has infinite effective viscosity for the low shear rate, thus limiting its range of applicability.

Mathematically, the Prandtl-Eyring model can be written as (Bird et al [20], Skelland [27])

$$
\tau_{y x}=A \sinh ^{-1}\left(\frac{1}{C} \frac{\partial u}{\partial y}\right)
$$

where $A$ and $C$ are flow consistency indices.

Introducing the dimensionless quantities,

$$
H^{\prime}(\eta)=\frac{\alpha F^{\prime \prime \prime}}{\left\{1+\gamma\left(F^{\prime \prime}\right)^{2}\right\}^{1 / 2}}
$$

where $\alpha=\frac{A}{\mu_{\infty} C}, \gamma=\frac{\rho U_{\infty}^{3}}{\mu L C^{2}}$ are dimensionless flow parameter.

Substituting it into the equation (29), we get

$$
\left.\begin{array}{l}
F^{\prime \prime \prime}=\frac{1}{3 \alpha}\left(F^{\prime 2}-2 F F^{\prime \prime}-G-3 M F^{\prime}\right) \sqrt{1+\gamma F^{\prime \prime 2}} . \\
2 F G^{\prime}+F^{\prime} G+\frac{1}{P_{r}} G^{\prime}=0 .
\end{array}\right\}
$$

Further, the expression of local skin-friction coefficient $C_{f}$ is:

$$
\left.\frac{1}{2} \sqrt{\operatorname{Re}} C_{f} \equiv \tau_{y x}\right|_{y=0}=\frac{\alpha}{\sqrt{\gamma}} \sinh ^{-1}\left\{\sqrt{\gamma} f^{\prime \prime}(0)\right\}
$$

\section{RESULTS AND DISCUSSIONS}

- The numerical solutions in a graphical form of nonlinear system (34) subject to the boundary conditions (31) are obtained using bvp4c solver in Matlab (Figs. 2-10). This is second order accurate and allows uniform and non-uniform grid size.

- Figures 2-4 are graphical representation of the profiles similarity variables $F^{\prime}, G$ and $F^{\prime \prime}(0)$ are related to velocity along $X$-axis, local shear stress and temperature respectively under the influence of magnetic field $M$. These figures mean that increase in $M$ causes the boundary layers to thicken.

- At this point it is worth noting that a similar kind of effects have been observed in the work of $\mathrm{Na}$ and Hansen [12] and T. Hayat et al. [30] for Power-law and Powel-Eyring Non-Newtonian fluids respectively.

- This warrants that the present work is consistent with earlier work, indeed we have analyze the most general case and one can studied any NonNewtonian fluid model using present analysis.

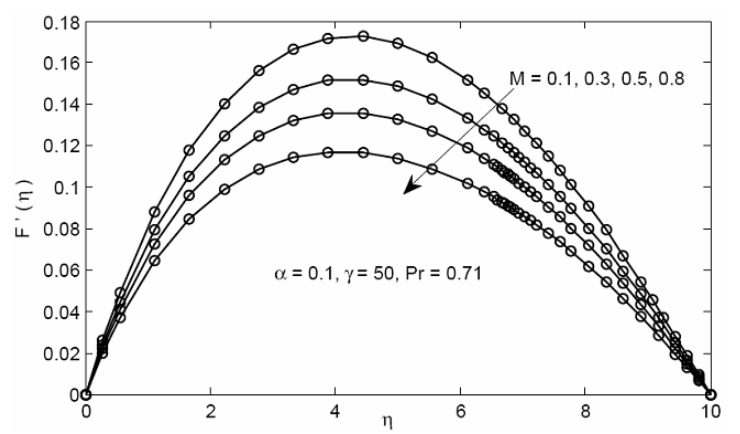

Figure 2. Magnetic fields effect on velocity profile

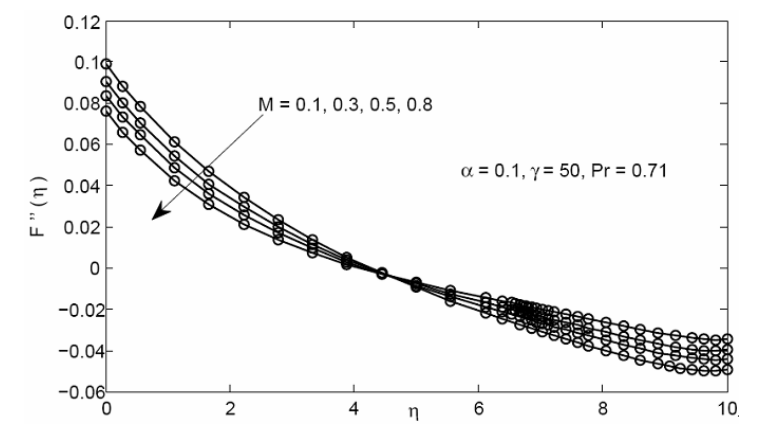

Figure 3. Magnetic field effects on local shear-stress profile

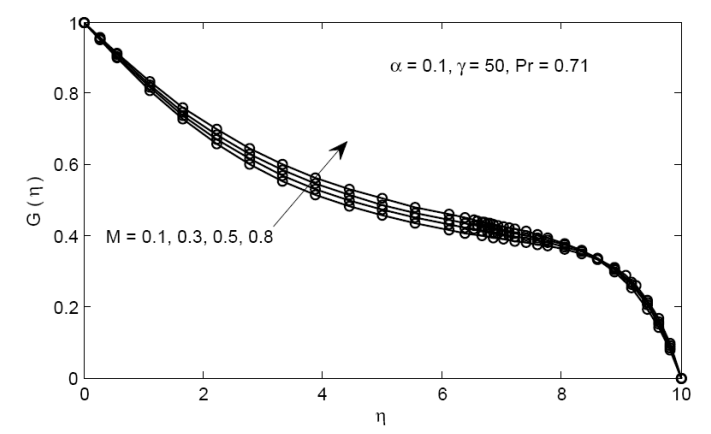

Figure 4. Magnetic field effects on temperature profile 


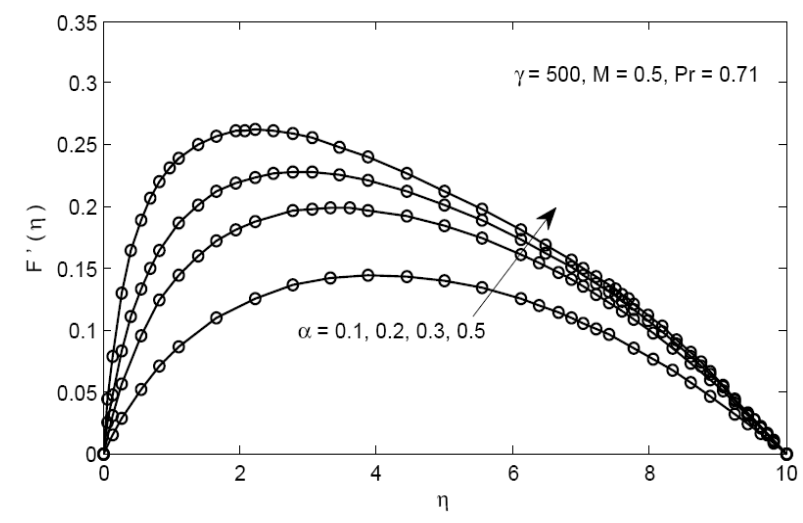

$5(a)$

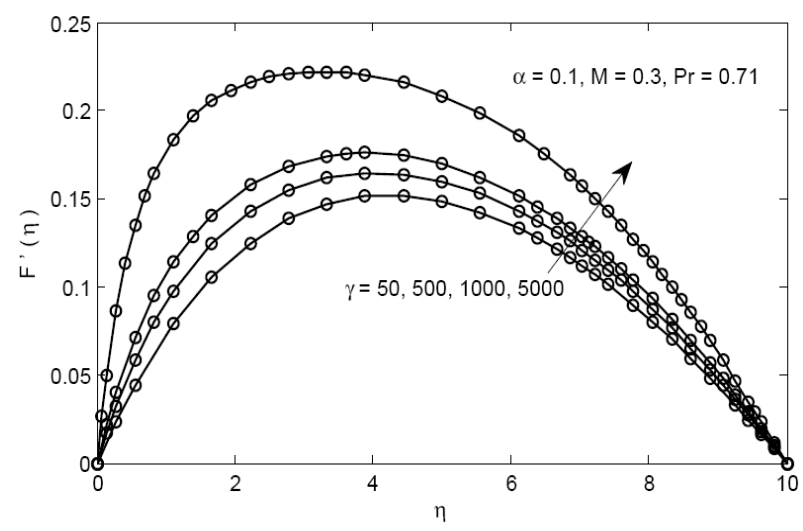

$5(\mathrm{~b})$

Figure 5. Influence of flow parameter on non-dimensional velocity

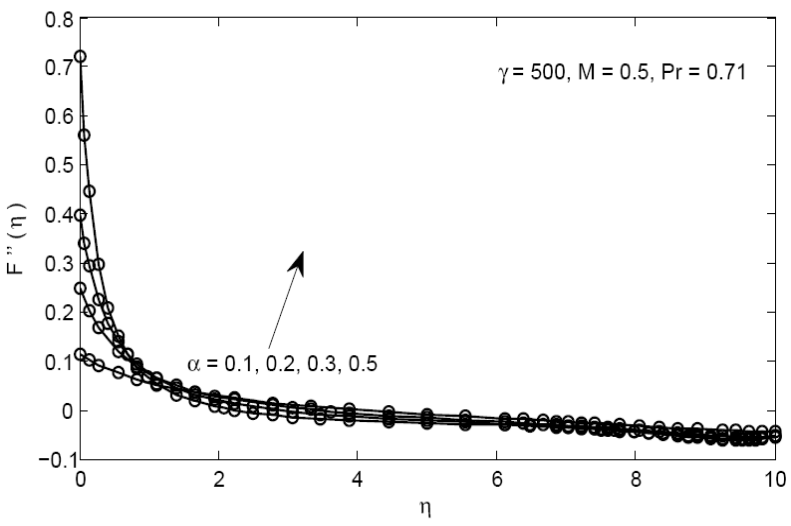

6(a)

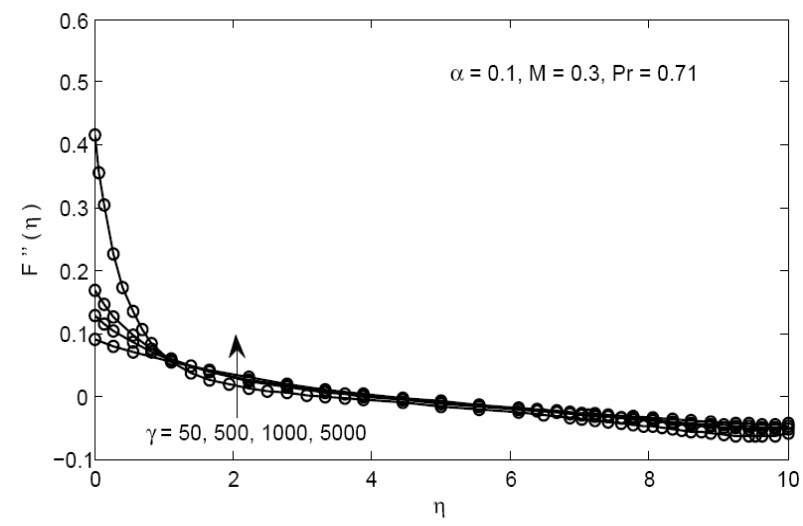

6(b)

Figure 6. Influence of flow parameter on non-dimensional local shear-stress

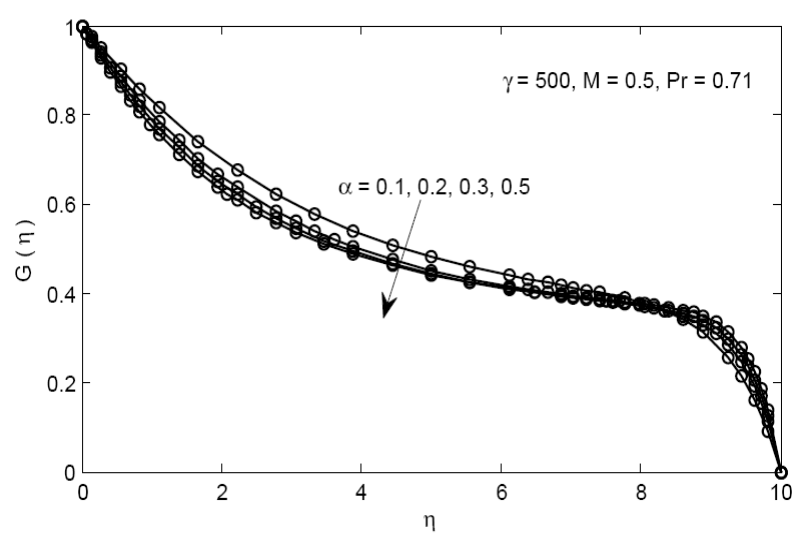

$7(a)$

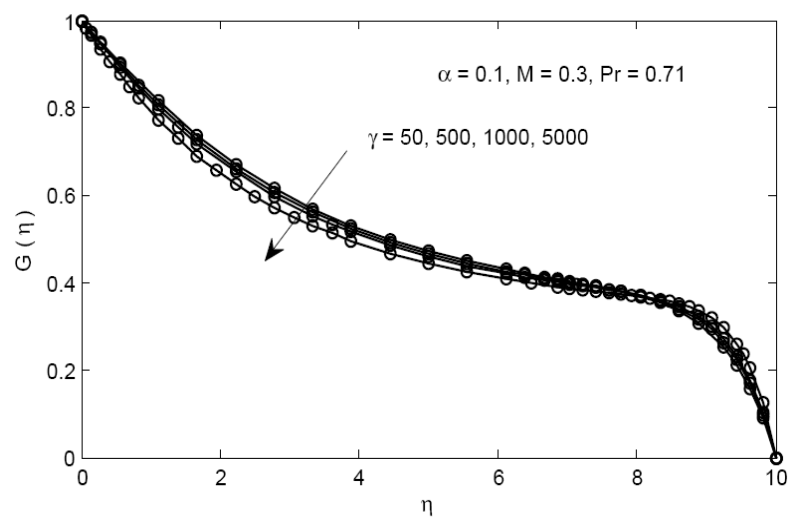

7(b)

Figure 7. Influence of flow parameter on non-dimensional temperature

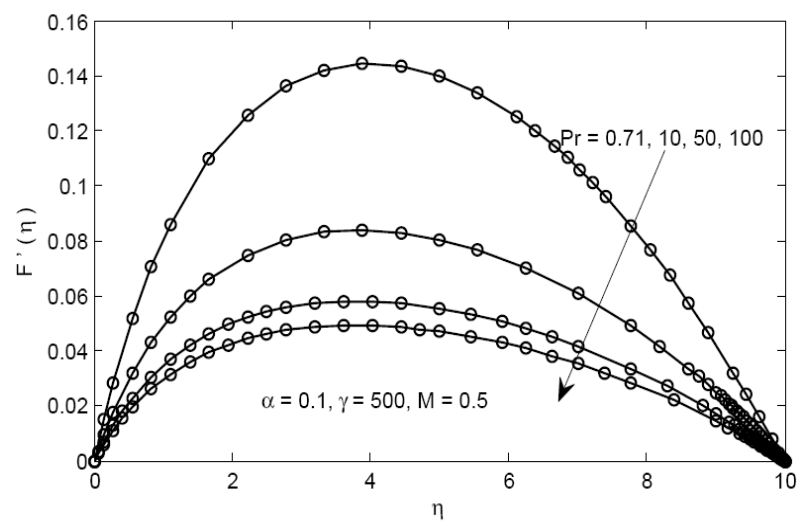

Figure 8. Effect of Prandtl number on dimensionless velocity of Prandtl Eyring fluid

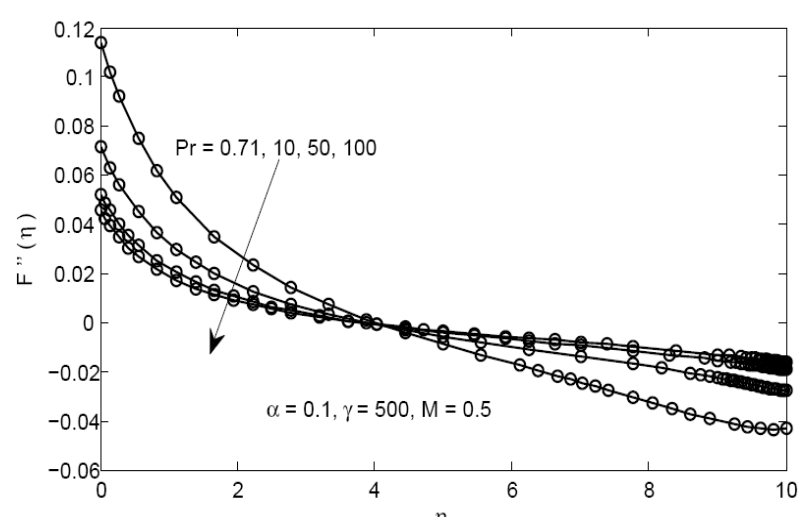

Figure 9. Effect of Prandtl number on skin-friction coefficient of Prandtl Eyring fluid 


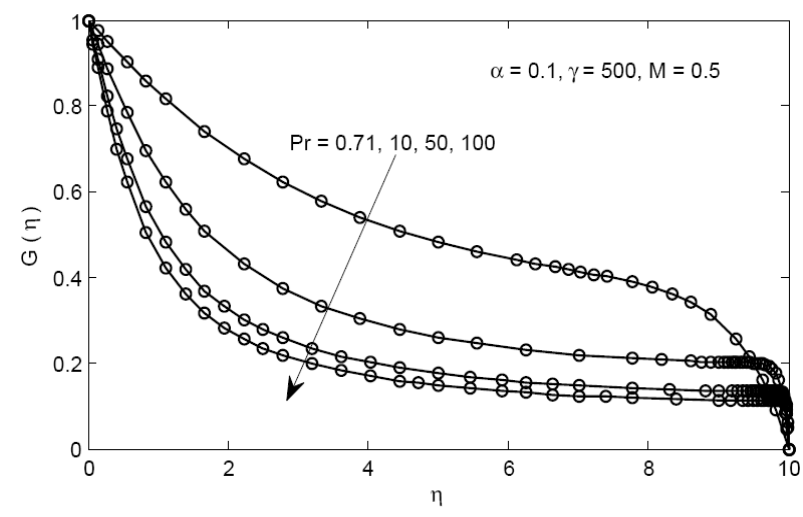

Figure 10. Temperature variation under the effect of PrandtI number on Prandtl Eyring fluid

- $\quad$ Figs. 5-7 display the effect of flow parameters $\alpha$ and $\gamma$ on similarity functions variables related to velocity along $X$ direction, local skin-friction and temperature. These figures depict boundary layer thickness decrease as the flow parameter $\alpha$ increases by controlling the flow parameter $\gamma$ and $M$. A similar trend can be observed for another flow parameter. This behavior of flow is consistent with Hayat et al. [30].

- Also, the rheological parameter $B$ and $\mu_{\infty}$ have an inverse relation with dimensionless parameter. Decrease in one of the rheological parameters means an increase in one of the flow parameter. Figs. 8-10 represent the effect of magnetic parameters, hence the decrease of boundary layer thickness.

- Figs. 8-10 display the influence of Prandtl number on fluid flow. These figures depict an increase in Prandtl number causing the boundary and thermal boundary layer thichness. The present results are the same as those mentioned in S. Panigrahi et al. [31]. This comparision gurranteed the validity of present analysus.

- It is worth noting that all solutions have derived for non-dimensional quantities and hence these results are applicable for all types of considered nonNewtonian fluids.

\section{CONCLUSION}

The deductive group symmetry method is applied to search similarity transformations to transform the partial differential system to ordinary differential system for the class of Non-Newtonian fluids. Numerical solutions are presented in a graphical form for Prandtl-Eyring fluids using Matlab. Effects of rheological parameters on the boundary layers are discussed in detail. It is found that change in all the dimensionless parameters and rheological parameters causes the boundary layers thickness. The analysis is made for generalized Non-Newtonian fluid and work of $\mathrm{Na}$ and Hansen [12] and T. Hayat et al. [30] are particular cases of he present work.

\section{ACKNOWLEDGMENT}

The authors express their gratitude to the unknown referees for their critical reviews and fruitful comments.

\section{REFERENCES}

[1] Oosthuizen, P.H. An introduction to convective Heat Transfer Analysis, McGraw-Hill. 1999.

[2] Soundalgekar, V. M., Free convection effects on the oscillatory flow past an infinite, vertical porous plate with constant suction II, Proc. R. Soc. London, Vol. A 333, pp 37-50. 1973,

[3] Soundalgekar, V. M., Free convection effects on the Stokes problem for an infinite vertical plate, J. Heat transfer, Trans. ASME, Vol 99, pp 499-501, 1977.

[4] Georgantopoulos, G. et al.: Free convection and mass transfer effects on the oscillatory flow of a dissipative fluid past an infinite vertical porous plate II, Czechoslovac. Jour. of Phy., B 31, pp 876884, 1981.

[5] Revankar, S. T., Natural convection effects on MHD flow past an impulsively started permeable vertical plate, Ind. J. Pure and Appl. Maths, Vol 14(4), pp 530-539, 1983.

[6] Soundalgekar, V. M., Free convection effects on the Stokes problem for an infinite vertical plate, J. Heat transfer, Trans. ASME, Vol. 99, pp 499-501, 1977.

[7] Kafousias, G., MHD thermal -diffusion effects on free convective and mass transfer flow over an infinite vertical moving plate, Astro.Phy.Space Sci, Vol. 192. pp 11-19, 1992.

[8] Ingham D. B, Pop I. (eds.), Transport Phenomena in Porous Media. Pergamon, Oxford., vol. I, 1998, vol. II, 2002.

[9] Nakayama, A., Shenoy, A. V., Combined forced and free convection heat transfer in Power-Law fluid-saturated porous media. Appl. Sci. Res. Vol. 50, pp. 83-95, 1993.

[10]Lee, S. Y. and Ames. W. F., Similarity solutions for non-Newtonian fluids. AIChE JI, Vol. 12, pp.700-708, 1966.

[11]Acrivos, A., A theoretical analysis of laminar natural convection heat transfer to Non-Newtonian fluids, AIChE. J., vol 6, no. 4, 584-590, 1960.

[12] Na, T. Y. and Hansen, A. G., Possible similarity solution of laminar natural convection flow of nonNewtonian fluids, Int. J. of heat and mass transfer, Vol 9, pp 261, 1966.

[13] Sarpakaya, T., Flow of non-Newtonian fluids in a magnetic field, AICh Journal Vol. 7, pp. 324-328, 19961.

[14] Andersson, H. I., Bech, K. H. and Dandapat, B. S., Magnetohydrodynamic flow of a power-law fluid over a stretching sheet, Int. J. Non-Linear Mech. Vol. 27, pp. 929-936, 1992.

[15] Martinson, L. K., Pavlov, K. B., Unsteady shear flows of a conducting fluid with a rheological power law, MHD Vol. 7, pp. 182-189, 1971.

[16] Samokhen, V. N., On the boundary-layer equation of MHD of dilatant fluid in a transverse magnetic field, MHD Vol. 3, pp. 71-77, 1987.

[17] Cortell, R., A note on magneto hydrodynamic flow of a power law fluid over a stretching sheet, Appl. Math. Comput. Vol. 168, pp. 557-566, 2005. 
[18] Saponkov, Y., Similar solutions of steady boundary layer equations in magnetohydrodynamic power law conducting fluids, Mech. Fluid Gas. Vol. 6 pp. 77-82, 1967.

[19]Liao Shi-Jun, On the analytic solution of magnetohydrodynamic flows of non-Newtonian fluids over a stretching sheet, J. Fluid Mech. Vol. 488, pp. 189-212, 2005.

[20] Bird, R. B., Stewart, W. E. and Lightfoot, E. M. Transport phenomena, John Wiley, New York, 1960.

[21] Abd-el-Malek, et al., Solution of the Rayleigh problem for a power law non-Newtonian conducting fluid via group method. Int. J. Eng. Sci. Vol. 40, pp. 1599-1609, 2002.

[22] Adnan, K. A., Hasmani, A. H. and Timol, M. G., A new family of similarity solutions of three dimensional MHD boundary layer flows of nonNewtonian fluids using new systematic grouptheoretic approach, Applied Mathematical Sciences Vol. 5, No.(27, pp. 1325-1336, 2011.

[23] Darji, R. M. and Timol, M. G., Deductive Group Theoretic Analysis for MHD Flow of a Sisko Fluid in a Porous Medium, Int. J. of Appl. Math and Mech. Vol. 7, No. 19, pp. 49-58, 2011.

[24] Darji, R. M. and Timol, M. G., Invariance analysis and similarity solution of heat transfer for MHD viscous power-law fluid over a non-linear porous surface via group theory, Int. J. Adv. Appl. Math. and Mech. Vol. 1, No. 2, pp. 116-132, 2013.

[25] Morgan A. J. A., The reduction by one of the number of independent variables in some systems of nonlinear partial differential equations. Quart. J. Math. Oxford Vol. 3, pp. 250-259, 1952.

[26] Moran, M. J. and Gaggioli, R. A., Reduction of the number of variables in system of partial differential equations with auxiliary conditions. SIAM J. Appl. Math. Vol. 16, pp. 202-215, 1968.

[27] Skelland, A. H. P., Non-Newtonian flow and heat transfer, John Wiley, New York, 1967.

[28] Gebhart B. and Pera, L., The nature of vertical natural convection flows resulting from the combined buoyancy effects of thermal and mass diffusion, Int. J. Heat Mass Transfer, Vol. 14, pp. 2025-2049, Zbl 223.76060, 1971.

[29] Gebhart, B., et al., Bouyancy-Induced Flows and Transport, Hemisphere Publishing Corporation, 1988. Zbl 699.76001.

[30] Hayat, T., et al., Similarity solutions for boundary layer equations of a Powel-Eyring fluid, Mathematical and Computational Applications, Vol. 18, No. 1, 62-70, 2013.
[31] Panigrahi, S., Reza, M. and Mishra. A. K., MHD effect of mixed convection boundary-layer flow of Powell-Eyring fluid past nonlinear stretching surface, Applied Mathematics and Mechanics, Vol. 35, No. 12, pp. 1525-1540, 2014.

\section{NOMENCLATURE}

$\begin{array}{ll}A, C & \text { Flow consistency indices } \\ B & \text { Magnetic field strength } \\ F, G, H & \text { Transformed dependent variables } \\ g & \text { Gravitational force } \\ G r & \text { Grashof number } \\ \mathrm{Pr} & \text { Prandtl number } \\ \operatorname{Re} & \text { Reynolds number } \\ u, v & \text { Components of velocity in } x, y \text { direction } \\ U & \text { Main stream velocity } \\ x, y & \text { Rectangular coordinates }\end{array}$

\section{Greek symbols}

$\begin{array}{ll}\alpha^{\prime} & \text { Thermal diffusivity } \\ \beta^{\prime} & \text { Volumetric thermal expansion coefficient } \\ \rho & \text { Density } \\ v & \text { Kinematics viscosity } \\ \mu & \text { Viscosity } \\ \psi & \text { Stream function } \\ \tau & \text { Shearing stress } \\ \Omega & \text { Functional relation of } \tau \text { and velocity } \\ \eta & \text { gradient } \\ \theta & \text { Transformed independent variables } \\ \theta_{w} & \text { Temperature distribution }\end{array}$

\section{ПОСТУПАК УТВРЪИВАЊА СЛИЧНОСТИ КОД СЛОБОДНОГ КОНВЕКТИВНОГ МХД СТРУЈАҢА У ГРАНИЧНОМ СЛОЈУ КЛАСЕ НЕНУТНОВСКОГ ФЛУИДА}

\section{Р.М. Дарји, М.Г. Тимол}

У раду се користи поступак симетрије дедуктивне групе за извођење трансформација сличности код слободног конвективног струјања у граничном слоју класе нењутновских флуида који прелазе преко дводимензионалне површине и теку под утицајем попречног магнетног поља. Нумеричка решења су добијена у графичком облику за одређени модел нењутновског флуида, тј. Прандтл-Ерингов флуид. Разматрају се значајне физичке величине као што је дистрибуција брзине, коефицијент спољашњег трења и температурне варијације. 